\title{
Catalysis of the Michael reaction by iron(III): calculations, mechanistic insights and experimental consequences
}

\author{
Silke Pelzer ${ }^{\mathrm{a}}$, Thomas Kauf ${ }^{\mathrm{b}}$, Christoph van Wüllen ${ }^{\mathrm{a}, *}$, Jens Christoffers ${ }^{\mathrm{b}, *}$ \\ ${ }^{a}$ Technische Universität Berlin, Institut für Chemie, Sekretariat C3, Straße des 17. Juni 135, D-10623 Berlin, Germany \\ ${ }^{\mathrm{b}}$ Universität Stuttgart, Institut für Organische Chemie, Pfaffenwaldring 55, D-70569 Stuttgart, Germany
}

Received 28 February 2003; received in revised form 28 May 2003; accepted 28 May 2003

Dedicated to Professor Ernst Otto Fischer on the occasion of his 85th birthday

\begin{abstract}
The Fe ${ }^{\mathrm{III}}$ catalysed Michael reaction of $\beta$-oxo esters $\mathbf{1}$ with methyl vinyl ketone (2a) and methyl acrylate (2b) as acceptors is investigated. The proposed mechanism, based on experimental results, is supported for the first time by ab initio calculations. Thereby different $\mathrm{Fe}^{\mathrm{III}}$ complexes 4, derived from the catalyst and $\mathbf{1}$, with either neutral $\left(\mathrm{H}_{2} \mathrm{O}\right)$ or anionic (a second diketonate $\left.\mathbf{1}\right)$ coligands are considered and their stabilities calculated. Ligand exchange in $\mathbf{4}$ by acceptors $\mathbf{2}$ gives intermediates $\mathbf{5}$ and subsequent $\mathrm{C}-\mathrm{C}$ bond formation affords complexes $\mathbf{6}$. Both $\mathbf{5}$ and $\mathbf{6}$ are found to be minima on the potential hypersurface and a pathway from $\mathbf{5}$ to 6 via transition states 7 could be identified. For the reaction of $4 \mathbf{a}\left(\mathrm{L}=\mathrm{H}_{2} \mathrm{O}\right)$ with $\mathbf{2 a}$, b no reactivity difference was found. The anionic coligand, however, causes a significant change in the reaction profile: due to the higher reaction barrier for the $\mathrm{C}-\mathrm{C}$ coupling for $\mathbf{2 b}$ (5d to $\mathbf{6 d}$ ) compared to $\mathbf{2 a}$ (5f to $\mathbf{6 f}$ ) a fast subsequent reaction and thus, catalytic turnover is inhibited.

(C) 2003 Elsevier B.V. All rights reserved.
\end{abstract}

Keywords: Michael addition; Iron complexes; Metal catalysis; Iron; DFT calculations; Chloride

\section{Introduction}

The conjugate addition of an enolate-commonly derived from a $\beta$-dicarbonyl compound $\mathbf{1}$-to an acceptor activated olefin such as methyl vinyl ketone (2a) results in a 1,5-dioxo constituted product 3 [1] (Scheme 1). Known as the Michael reaction it is among the most important $\mathrm{C}-\mathrm{C}$ bond forming reactions. Traditional catalysts for this process are Brönstedt bases such as tertiary amines, alkali alkaloxides or hydroxides. However, the strongly basic conditions are often a limiting factor since they can cause undesirable side and subsequent reactions. Therefore, a number of metal catalysts have been reported, which allow conversion under milder conditions [2]. In 1997, iron(III) chloride hexahydrate was introduced by our group; to date this is

\footnotetext{
* Corresponding authors. Tel.: +49-711-685-4283; fax: +49-711685-4269 (J.C.); fax: +49-30-314-23 727 (C.v.W.).

E-mail addresses: christoph.vanwullen@chem.tu-berlin.de (C. van Wüllen), jchr@po.uni-stuttgart.de (J. Christoffers).
}

the most efficient catalyst for Michael reactions of $\beta$ diketones and $\beta$-oxo esters with enones, allowing quantitative conversions under very mild conditions and even without the need of any solvent $[3,4]$. With regard to the mechanism of the iron(III) catalysis proposals have been made earlier. In this paper, we wish to summarize experimental information for the mechanistic proposal and support our suggestions with $\mathrm{ab}$ initio calculations. Furthermore, an improvement of the iron(III) catalysis was inspired by our theoretical studies.

\section{Results and discussion}

\subsection{Experimental indications and mechanistic proposal}

In order to support a single-centre mechanism the rate of the reaction of $\beta$-oxo ester 1a with 2a was studied with varying amounts of the catalyst $\mathrm{FeCl}_{3} \cdot 6 \mathrm{H}_{2} \mathrm{O}(0.5-$ $5 \mathrm{~mol} \%)$. Chloroform was used as the solvent $[c(\mathbf{1 a})=$ 


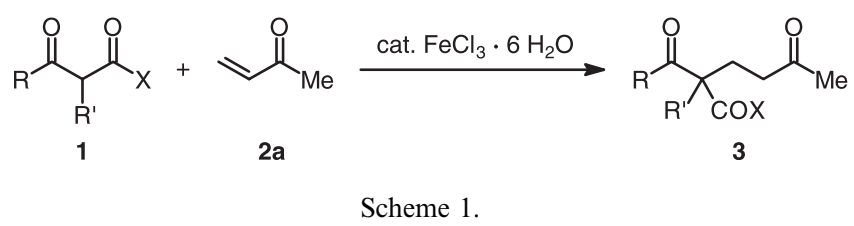

$1.95 \mathrm{~mol} \mathrm{dm}^{-3}$ ]. Conversions were determined by GLC with hexadecane as an internal standard in the reaction mixtures. Within the first $20 \%$ of conversions the reaction rates are almost independent of the substrate concentrations, thus zero order in $\mathbf{1 a}$ and $\mathbf{2 a}\left(\mathrm{d} c=k_{0} \mathrm{~d} t\right)$. The initial rate with $1 \mathrm{~mol} \%$ iron(III) was $k_{0}=0.11 \mathrm{~mol}$ $\mathrm{dm}^{-3} \mathrm{~h}^{-1}$ and defined as $k_{\mathrm{rel}, 0}=1$. The relative initial rates $k_{\text {rel, } 0}$ have been plotted in Fig. 1 versus the amount of the catalyst. A linear relationship represents a first order of the reaction in $\mathrm{Fe}(\mathrm{III})$, thus, is strongly indicating a single-centre mechanism of the iron catalysis.

The catalytic activity of $\mathrm{FeCl}_{3} \cdot 6 \mathrm{H}_{2} \mathrm{O}$ is closely related to its ability to give dionato chelate complexes $\mathbf{4}$ with $\beta$ dicarbonyl compounds. Without prior deprotonationeven in Brönstedt acidic media - these deep coloured iron complexes are instantly formed [5]. With this property $\mathrm{Fe}(\mathrm{III})$ is unique among all other transition metals, which require a stoichiometric amount of base for dionato-complex formation. Known for over 100 years, the significant colour of these complexes has been utilized for the detection of $\beta$-oxo esters and $\beta$-diketones.

The ligand in a dionato complex $\mathbf{4}$ is planar and it is particularly stabilized by $\pi$-delocalisation. Besides this thermodynamic stability the iron centre has 17 valence electrons in an octahedron, thus, its coordination sphere is kinetically labile. By ligand exchange the acceptor $\mathbf{2}$ is

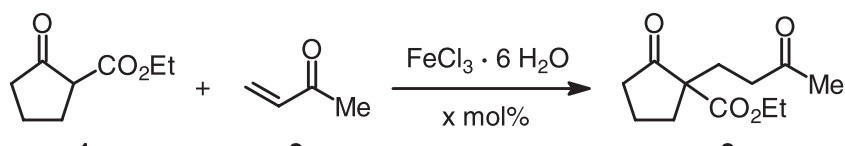

$1 \mathrm{a}$ $2 \mathbf{a}$ $3 \mathbf{a}$

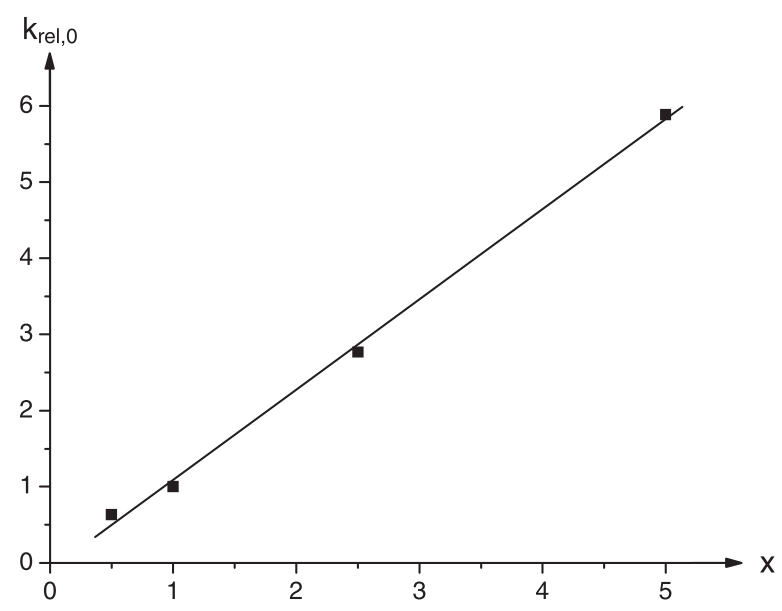

Fig. 1. Reaction order in iron(III).

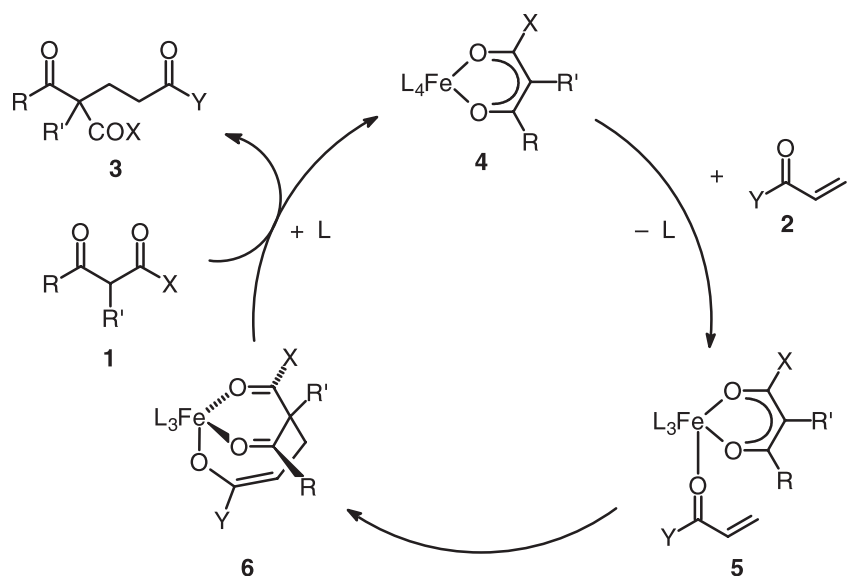

Scheme 2. Mechanistic proposal; $\mathrm{L}=\mathrm{H}_{2} \mathrm{O}$.

proposed to coordinate at a vacant site to form species $\mathbf{5}$ (Scheme 2). The function of the centre metal is not only to hold the acceptor in proximity to the donor. Additionally, the acceptor is activated by the Lewis acidity of the metal. Subsequently, the nucleophilic carbon atom of the dionato ligand is alkylated by the coordinating acceptor to form the bicyclic intermediate 6 with a coordinating enolate side chain. From this species $\mathbf{6}$ the product $\mathbf{3}$ is liberated readily and complex $\mathbf{4}$ regenerated by ligand exchange, since $\pi$-delocalisation is obviously impossible in structure 6.

The idea of a one-centre template reaction is not only supported by the first order kinetics as outlined above, but also strongly indicated by the fact that only acceptors are converted, which can achieve a s-cisconformation between the carbonyl group and the $\mathrm{C}-\mathrm{C}$ double bond. This is impossible for cyclic enones and highly disfavoured in compounds like mesityl oxide bearing an additional $Z$-substituent. And indeed, little or no reactivity is observed for these acceptors. Likewise, propiolates cannot have a s-cis-like conformation. As mentioned above, different iron compounds such as $\mathrm{Fe}(\mathrm{acac})_{3}$ and anhydrous $\mathrm{FeCl}_{3}$ are significantly less active than the hexahydrate, because they do not offer readily a vacant coordination site for the enone. In these cases, enone activation has to be realized by application of an additional Lewis acid [6].

\subsection{Calculations}

\subsubsection{Water as coligands}

While the mechanistic proposal depicted in Scheme 2 is in accordance with the experimental observations, direct experimental support for the catalytic cycle and the intermediates is lacking so far. One of the reasons is that all iron(III) species are paramagnetic making NMR investigations rather difficult. Moreover, we did not succeed to date in crystallization of any of the proposed intermediates 4-6. Therefore we decided to perform 
quantum chemical density functional calculations (see Section 3 for computational details) as an additional source of information. For these calculations methyl 2methyl-3-oxobutyrate (1b) was used as the $\beta$-dicarbonyl compound and both methyl vinyl ketone $(\mathbf{2 a}, \mathrm{Y}=\mathrm{Me})$ and methyl acrylate $(\mathbf{2 b}, \mathrm{Y}=\mathrm{OMe})$ as the Michael acceptors (Scheme 3). Experimentally, the ester $\mathbf{2 b}$ shows no reactivity in contrast to ketone $\mathbf{2 a}[4 a, 4 b]$, and thus, we were interested to investigate if this different behaviour could be reproduced and explained by our calculations.

Since ligand exchange is supposed to be facile in the coordination sphere of the iron ion [7], we computed the relative stabilities of $\mathbf{4 a}$ and $\mathbf{5 a}, \mathbf{b}$ (Scheme 3 ) but did not calculate any pathway from $\mathbf{4 a}$ to $\mathbf{5 a}, \mathbf{b}$. For the $\mathrm{C}-\mathrm{C}$ coupling step $\mathbf{5 a}, \mathbf{b} \rightarrow \mathbf{6 a}, \mathbf{b}$, however, transition states $\mathbf{7 a}, \mathbf{b}$ have been located to determine the reaction barrier.

The resulting energy profiles of the reaction of $\mathbf{4 a}$ with $\mathbf{2 a}$ and $\mathbf{2 b}$ are shown in Fig. 2. The intrinsic reaction barriers of $78 \mathrm{~kJ} \mathrm{~mol}^{-1}$ for methyl vinyl ketone (2a) and of $72 \mathrm{~kJ} \mathrm{~mol}^{-1}$ for methyl acrylate (2b) would imply reasonably fast reaction rates at ambient temperature. This result gives positive evidence to the mechanistic proposal for the first time, since structures $\mathbf{5 a}, \mathbf{b}$ and $\mathbf{6 a}, \mathbf{b}$ turn out to be minima on potential hypersurface and a pathway with the transition states $7 \mathbf{a}, \mathbf{b}$ could be identified. However, this finding is incomplete, because no substantial reactivity difference for $\mathbf{2} \mathbf{a}$ and $\mathbf{2} \mathbf{b}$ would be predicted by these calculations as is found experimentally. Therefore the presence of triaqua complexes $\mathbf{5 a}$ and $\mathbf{5 b}$ as the reacting intermediates seems to be an oversimplified picture.

\subsubsection{Anionic coligands}

$\mathrm{Up}$ to now, only neutral coligands $\mathrm{L}=\mathrm{H}_{2} \mathrm{O}$ were considered in our calculations of 4, 5 and $\mathbf{6}$. However, the high charge of the iron centre gives high probability to the coordination of a second diketonate, which is merely a "spectator" ligand in the C-C coupling step.<smiles>COC(=O)C(C(C)=O)[N+](=O)[O-]</smiles>

1b<smiles>[Y]C(=O)C=C</smiles>

2a $(\mathrm{Y}=\mathrm{Me})$ $\mathbf{2 b}(\mathrm{Y}=\mathrm{OMe})$<smiles>COC1=C(C)OP(O)O1</smiles>

$4 a$

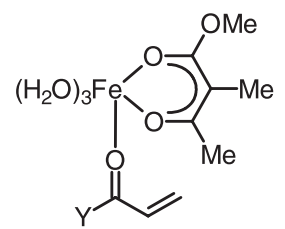

$5 \mathbf{a}(\mathrm{Y}=\mathrm{Me})$

$\mathbf{5 b}(\mathrm{Y}=\mathrm{OMe})$

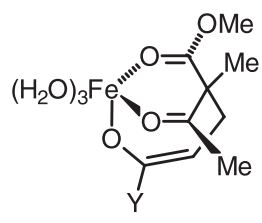

$6 \mathbf{a}(\mathrm{Y}=\mathrm{Me})$ 6b $(\mathrm{Y}=\mathrm{OMe})$

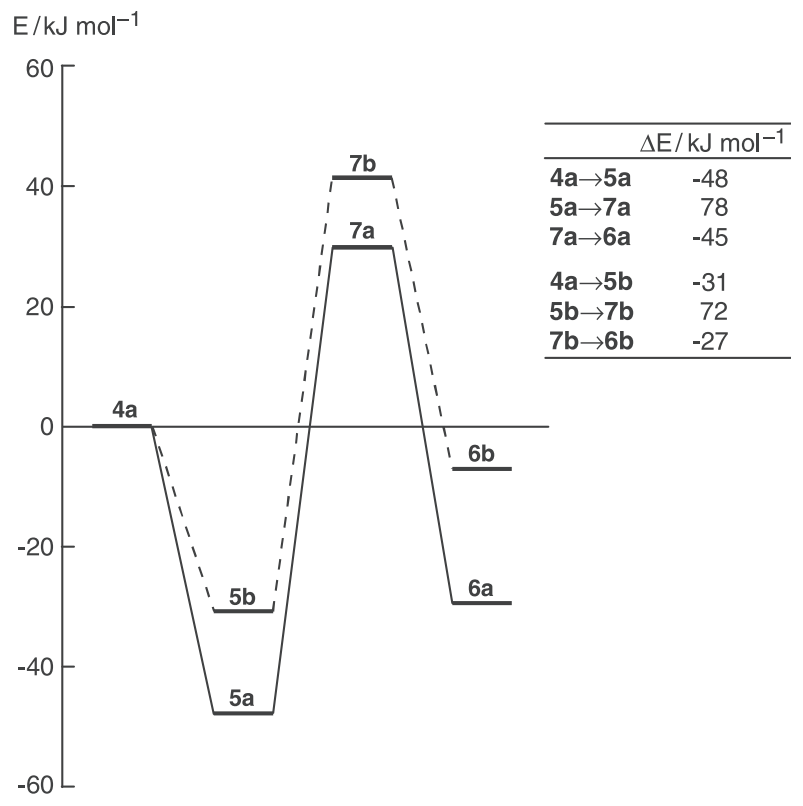

Fig. 2. Energy profiles for reactions with methyl vinyl ketone (2a) (-) and methyl acrylate (2b) (- - - ). Shown are the B3LYP results.

We have to consider two different coordination models (Scheme 4). In the meridional coordination realized in $\mathbf{4 b}$ the four dionato oxygen atoms occupy four equatorial corners of the octahedron, while in the facial structure $\mathbf{4 c}$ four oxygen atoms occupy the corner of two adjacent faces of the octahedron. For simplicity cis or trans-isomers have not been considered. According to our calculations, $\mathbf{4 c}$ is slightly more stable than $\mathbf{4 b}$ (by 11 $\mathrm{kJ} \mathrm{mol}^{-1}$ ).

Complexes 5c and 5d (Scheme 4) are the first intermediates resulting from isomeric diaqua-complexes $\mathbf{4 b}$ and $\mathbf{4 c}$ by ligand exchange of water with methyl

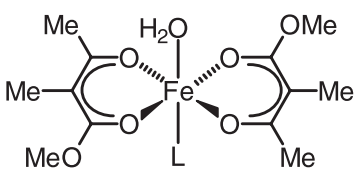

4b $\left(L=\mathrm{H}_{2} \mathrm{O}\right)$

$5 c(L=2 b)$

$5 \mathbf{e}(\mathrm{L}=\mathbf{2 a})$

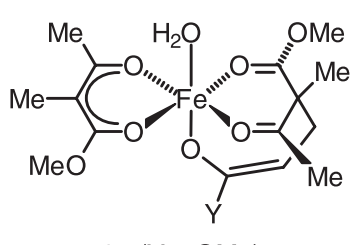

$6 c(\mathrm{Y}=\mathrm{OMe})$ $6 e(Y=M e)$<smiles></smiles>

$4 c\left(\mathrm{~L}=\mathrm{H}_{2} \mathrm{O}\right)$

$5 d(L=2 b)$

$5 f(L=2 a)$

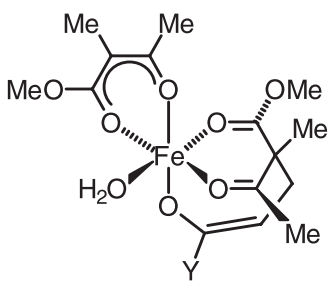

6d $(\mathrm{Y}=\mathrm{OMe})$ 6f $(Y=M e)$

Scheme 3.

Scheme 4. 


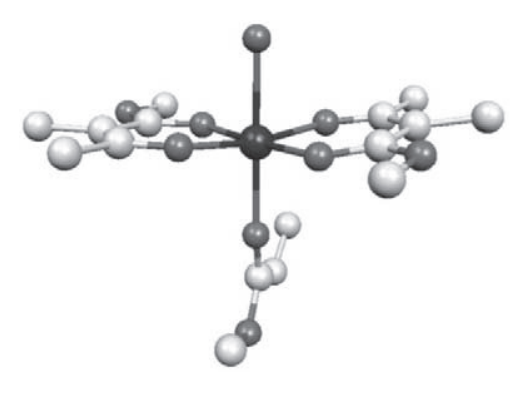

$5 c$

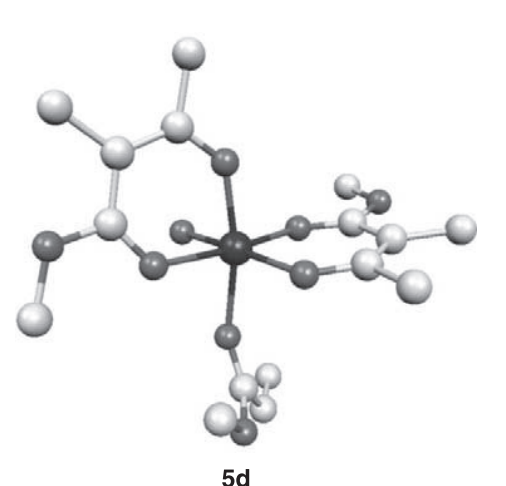

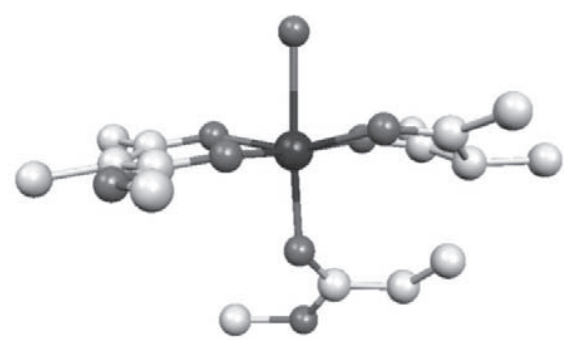

$7 c$

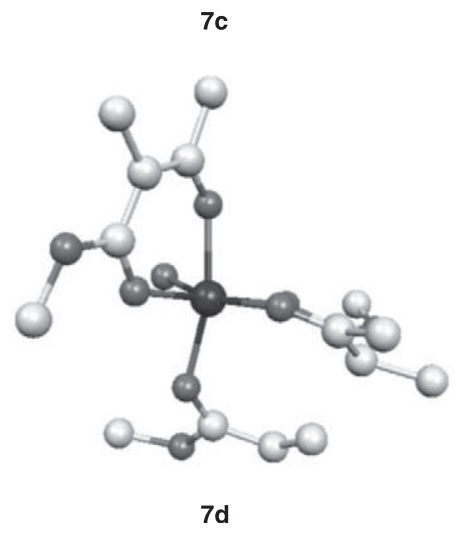

Fig. 3. Calculated structures for the meridional coordination in ground (5c) and transition state (7c) and the facial coordination in ground (5d) and

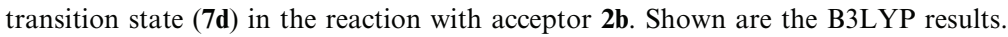

acrylate (2b). Structures $\mathbf{7 c}$ and $\mathbf{7 d}$ are the transition states derived from $\mathbf{5 c}$ and $\mathbf{5 d}$, respectively. The calculated structures are presented in Fig. 3. In particular, in transition state $\mathbf{7 c}$ generated from the meridional isomers $\mathbf{4 b}$ and $\mathbf{5 c}$, the $\alpha, \beta$-unsaturated carbonyl moiety is nearly coplanar with both $\beta$-diketonato ligands. In the facial isomers, 5d and 7d, water occupies the fourth equatorial position. The energy profiles of both, the meridional and the facial coordinated complexes derived from $\mathbf{4 b}$ and $\mathbf{4 c}$, are shown in Fig. 4.

The "spectator" diketonate causes a substantial change in the reaction profile. For the meridional case, the intrinsic reaction barrier for the $\mathrm{C}-\mathrm{C}$ coupling step with ketone $\mathbf{2 a}$ (from $\mathbf{5 e}$ to $\mathbf{6 e}$ via transition state $\mathbf{7 e}$ ) is now $63 \mathrm{~kJ} \mathrm{~mol}^{-1}$ and much lower than this step with acrylate $\mathbf{2 b}$ (from $\mathbf{5 c}$ to $\mathbf{6 c}$ via $7 \mathbf{c}$ ) being $97 \mathrm{~kJ} \mathrm{~mol}^{-1}$. For both acceptors the facial arrangement of the $\mathrm{C}-\mathrm{C}$ coupling step is more unfavourable than the meridional coordination (ketone 2a: from $\mathbf{5 f}$ to $\mathbf{6 f}$ via $\mathbf{7 f}, 82 \mathrm{~kJ}$ $\mathrm{mol}^{-1}$; acrylate $\mathbf{2 b}$ : from $\mathbf{5 d}$ to $\mathbf{6 d}$ via $\mathbf{7 d}, 99 \mathrm{~kJ} \mathrm{~mol}^{-1}$ ). Although the facial structure is $13 \mathrm{~kJ} \mathrm{~mol}^{-1}$ more stable than the meridional one, we can determine from the Curtin-Hammett-postulate that the meridional structure is the active catalytic species due to the lower transition state energy. The barrier heights of the complexes discussed in Section 2.2.1 (72 and $78 \mathrm{~kJ}$ $\mathrm{mol}^{-1}$ compared to $63 \mathrm{~kJ} \mathrm{~mol}^{-1}$ ) also exclude these complexes as the reactive species.

In a competing experiment with a 1:1 mixture of both acceptors $\mathbf{2 a}$ and $\mathbf{2 b}$ with catalytic amounts of $\mathrm{FeCl}_{3}$. $6 \mathrm{H}_{2} \mathrm{O}$ no conversion of $\mathbf{1 b}$ with $\mathbf{2 a}$ is observed in the

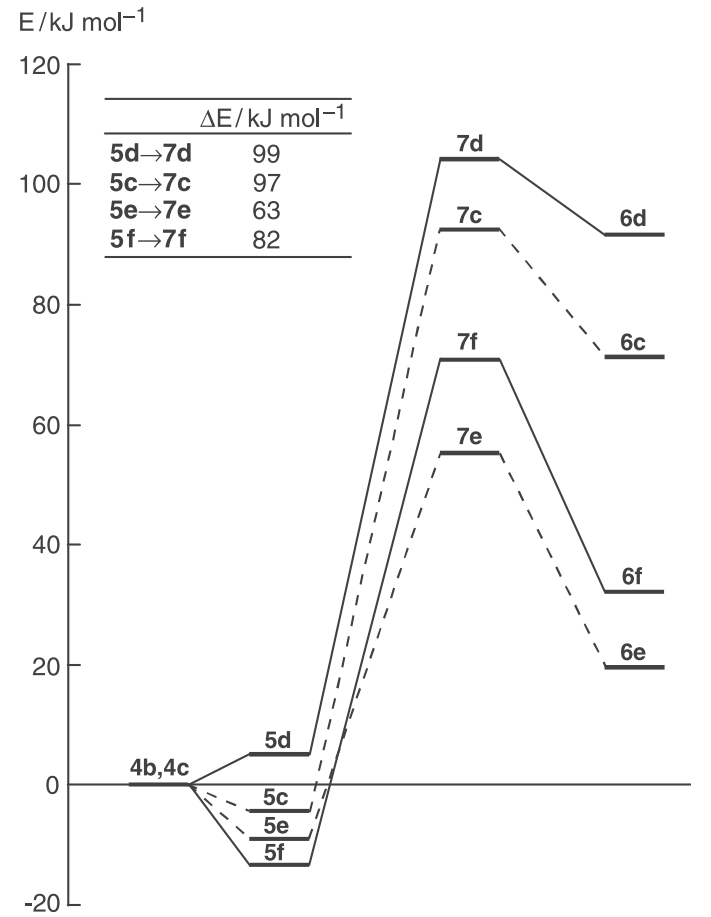

Fig. 4. Energy profiles of the two facial (4c) and meridional (4b) coordinated complexes. Reaction of $\mathbf{4 c}$ and $\mathbf{4 b}$ with methyl acrylate (2b) results in $5 \mathbf{d}-\mathbf{7 d}(-)$ and $\mathbf{5 c - 7 c}(--)$, respectively; reaction of $4 \mathbf{c}$

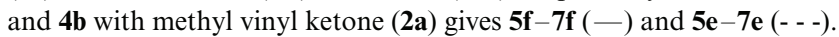
Results taken from the B3LYP calculations.

presence of $\mathbf{2 b}$. Thus, the acrylate $\mathbf{2 b}$ effectively inhibits any iron catalysed conversion. This observation, however, cannot be explained without further investigations, 
because the exchange of a water ligand by $\mathbf{2 a}$ is more favourable than by $\mathbf{2 b}\left(4 \mathrm{~kJ} \mathrm{~mol}^{-1}\right.$ for the meridional and $16 \mathrm{~kJ} \mathrm{~mol}^{-1}$ for the facial arrangement).

Negative coligands L strongly modulate the proton affinity of $\mathbf{4}$, an important issue that we have not discussed so far. The proton affinity of the anionic diketonate of $\mathbf{1 b}$ is, as expected, much higher than of neutral solvents like water, 2a, etc., such that in a mixture of $\mathbf{1 b}$ and $\mathbf{2 a}$, deprotonation of $\mathbf{1 b}$ (without adding a base) is unfavourable. On the other hand, the proton affinity of $\mathbf{4 a}$ with neutral coligands $\mathrm{L}$ is quite low mainly for electrostatic reasons, since $\mathbf{4 a}$ is still a dication (see Table 1 for gas phase proton affinities). This means that upon coordination the acidity of $\mathbf{1 b}$ is increased so much that it would easily protonate another molecule in the environment. Negative coligands increase the proton affinity as in $\mathbf{4 b}$ and $\mathbf{4 c}$ so much that it is eventually protonated by the acidic reaction mixture.

Now the question arises how the presence of chloride ions (from the catalyst $\mathrm{FeCl}_{3} \cdot 6 \mathrm{H}_{2} \mathrm{O}$ ) affects the reactivity. Our gas phase calculations predict exchange of water by chloride ion in model 4a to be highly exothermic ( $\left.818 \mathrm{~kJ} \mathrm{~mol}^{-1}\right)$ which can already be anticipated from electrostatic effects. The computed value is certainly very large, because chloride is likely to have a higher solvation energy than water, but nevertheless indicates that chloride will most probable bind to the iron centre in the reaction mixture, thus reducing the ability of iron to coordinate diketonates (which requires simultaneous protonation of the solvent). This is probably the reason for the decrease of the catalyst reactivity in presence of chloride ions (vide infra), since calculations show that the reaction barrier for $\mathrm{C}-\mathrm{C}$ coupling $(\mathbf{6} \rightarrow \mathbf{5})$ is increased to $83 \mathrm{~kJ} \mathrm{~mol}^{-1}$ if one of the diketonates is replaced by chloride and a water molecule compared to the transition barrier of 63 $\mathrm{kJ} \mathrm{mol}{ }^{-1}$ for $\mathbf{5 e} \rightarrow 7 \mathbf{e}$.

Table 1

Proton affinities calculated with the B3LYP functional and the TZVP basis set including zero point energy and thermal corrections

\begin{tabular}{ll}
\hline Compound & Proton affinity $\left(\mathrm{kJ} \mathrm{mol}^{-1}\right)$ \\
\hline $\mathbf{1 b}$ (diketonate anion) & 1455 \\
$\mathbf{1 b}$ & 883 \\
$\mathbf{2 a}$ & 807 \\
$\mathbf{2 b}$ & 813 \\
$\mathbf{4 a}$ & 193 \\
$\mathbf{4 c}$ (first protonation) & 669 \\
$\mathbf{4 c}($ second protonation) & 304 \\
$\mathbf{4}\left(4 \mathrm{~L}=\mathrm{Cl}^{-}\right.$and $\left.3 \mathrm{H}_{2} \mathrm{O}\right)$ & 590 \\
$\mathbf{4}\left(4 \mathrm{~L}=2 \mathrm{Cl}^{-}\right.$and $\left.2 \mathrm{H}_{2} \mathrm{O}\right)$ & 934 \\
\hline
\end{tabular}

\subsection{Experimental consequences}

As outlined above, our calculations suggest an acceleration of the iron catalysed conversion in the absence of anionic spectator ligands such as chloride. Consequently, we performed the reaction of donor 1a with $\mathbf{2 a}$ in the absence of a coordinating counterion and moreover, we studied the influence of chloride ion concentration on the initial rate [8]. In detail, we applied $0.7 \mathrm{~mol} \%$ of $\mathrm{Fe}\left(\mathrm{ClO}_{4}\right)_{3} \cdot 9 \mathrm{H}_{2} \mathrm{O}$ [9] as the catalyst and a substrate concentration of $c(\mathbf{1 a})=1.91 \mathrm{~mol} \mathrm{dm}^{-3}$ in $\mathrm{CHCl}_{3}$ with again hexadecane as an internal standard. In this experiment an initial rate of $k_{0}=0.64 \mathrm{~mol} \mathrm{dm}^{-3} \mathrm{~h}^{-1}$ was observed. This rate $\left(k_{\mathrm{rel}, 0}=1\right)$ is compared with results obtained in the presence of additional chloride ions in the reaction mixture added as benzyltriethylammonium chloride $\mathrm{BnEt}_{3} \mathrm{~N}^{+} \mathrm{Cl}^{-}$. In Fig. 5 the relative initial rates $k_{\text {rel,0 }}$ are plotted versus the chloride ion concentrations [relatively to Fe(III)], clearly indicating a linear, inhibiting influence of these counterions.

From this result, an optimised protocol for the iron catalysis was conduced, applying iron(III) perchlorate as the catalyst. With $0.35 \mathrm{~mol}^{\%}$ of $\mathrm{Fe}\left(\mathrm{ClO}_{4}\right)_{3} \cdot 9 \mathrm{H}_{2} \mathrm{O}$ quantitative conversions are achieved within $12 \mathrm{~h}$ (Scheme 5). Thus, the amount of catalyst was lowered to about $1 / 6$ compared to the amount of $\mathrm{FeCl}_{3} \cdot 6 \mathrm{H}_{2} \mathrm{O}$ used for the same reaction in the to date optimal protocol [10].

\section{Experimental}

3.1. Ethyl 2-oxo-1-(3-oxobutyl)cyclopentanecarboxylate (3a) with $\mathrm{Fe}\left(\mathrm{ClO}_{4}\right)_{3} \cdot 9 \mathrm{H}_{2} \mathrm{O}$ as the catalyst

Enone 2a (15.0 ml, $12.7 \mathrm{~g}, 182 \mathrm{mmol})$ was added to a mixture of $\mathrm{Fe}\left(\mathrm{ClO}_{4}\right)_{3} \cdot 9 \mathrm{H}_{2} \mathrm{O}(0.283 \mathrm{~g}, 0.55 \mathrm{mmol}, 0.35$ $\mathrm{mol} \%)$ and oxo ester 1a $(25.0 \mathrm{~g}, 160 \mathrm{mmol})$ within $1 \mathrm{~h}$

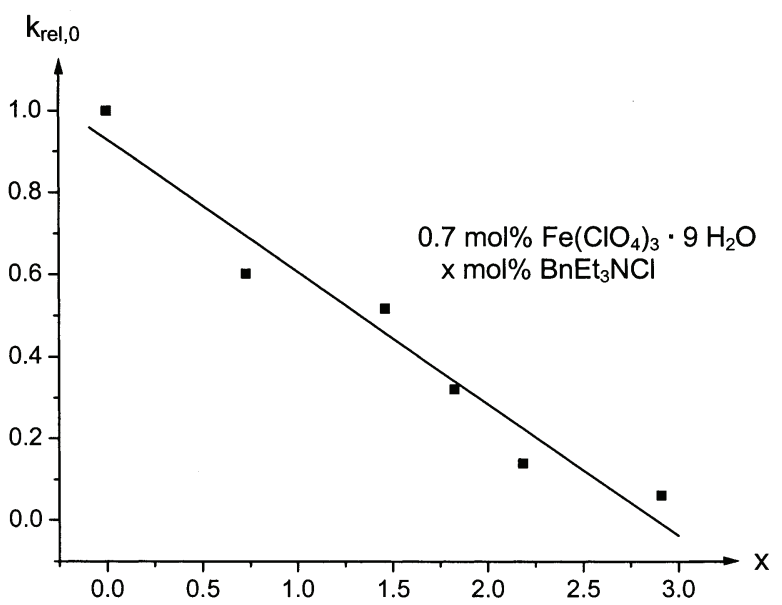

Fig. 5. Inhibition effect on the iron(III) catalysed conversion of donor 1a with acceptor $\mathbf{2 a}$. 


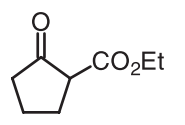

1a

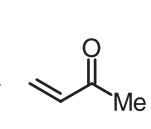

2a

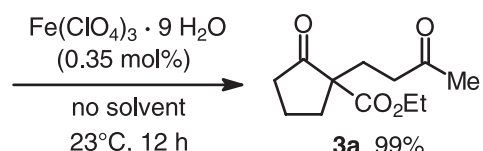

3a, $99 \%$
Scheme 5.

using a syringe pump. During this time the mixture was kept at ambient temperature (water bath). The resulting mixture was stirred for $12 \mathrm{~h}$ at room temperature, then all volatile materials were removed under reduced pressure. The product was diluted with tert-butyl methyl ether $(100 \mathrm{ml})$, filtered through a column of $\mathrm{SiO}_{2}(150 \mathrm{~g})$ and flushed with tert-butyl methyl ether (1.3 1). After concentration, the crude product was kept under high vacuum for $8 \mathrm{~h}$ to remove traces of the solvent. This procedure gave $36.0 \mathrm{~g}(159 \mathrm{mmol}, 99 \%)$ analytically pure product 3a. Anal. calc. for $\mathrm{C}_{12} \mathrm{H}_{18} \mathrm{O}_{4}$ (226.3): C, 63.70; H, 8.02. Found: C, 63.77; H, 8.22\%. The spectroscopic data are in accordance with the literature [10].

\subsection{Typical procedure for kinetic measurements}

A mixture of $\mathrm{FeCl}_{3} \cdot 6 \mathrm{H}_{2} \mathrm{O}(57 \mathrm{mg}, 0.21 \mathrm{mmol})$ and oxo ester 1a $(0.623 \mathrm{~g}, 3.99 \mathrm{mmol})$ was stirred for $30 \mathrm{~min}$. Then hexadecane $(0.225 \mathrm{~g}, 9.94 \mathrm{mmol})$ as an internal standard and chloroform $(0.80 \mathrm{ml})$ were added. By addition of enone $2 \mathrm{a}(0.336 \mathrm{~g}, 4.79 \mathrm{mmol})$ the reaction was started. At the given time intervals (after 1, 5, 10 and then in steps of $20 \mathrm{~min}$ ) aliquots were taken from the reaction mixture. After filtration through $\mathrm{SiO}_{2}(0.5$ $\mathrm{cm})$ with $\mathrm{CH}_{2} \mathrm{Cl}_{2}(6 \mathrm{ml})$, the samples were analysed by GLC.

\subsection{Typical procedure for the determination of the influence of the chloride ion}

A mixture of $\mathrm{Fe}\left(\mathrm{ClO}_{4}\right)_{3} \cdot 9 \mathrm{H}_{2} \mathrm{O}(24.9 \mathrm{mg}, 48.2 \mu \mathrm{mol})$ and oxo ester 1a $(1.04 \mathrm{~g}, 6.66 \mathrm{mmol})$ was stirred for 30 min. Then hexadecane $(0.40 \mathrm{ml}, 0.31 \mathrm{~g}, 1.36 \mathrm{mmol})$ as an internal standard, chloroform $(1.40 \mathrm{ml})$ and benzyltriethylammonium chloride $(8.0 \mathrm{mg}, 35.6 \mu \mathrm{mol})$ were added. By addition of the enone $2 \mathrm{a}(0.591 \mathrm{~g}, 8.44 \mathrm{mmol})$ the reaction was started. At the given time intervals (after 1, 5, 10 and then in steps of $20 \mathrm{~min}$, later in steps of $30 \mathrm{~min}$ ) aliquots were taken from the reaction mixture. After filtration through $\mathrm{SiO}_{2}(0.5 \mathrm{~cm})$ with $\mathrm{CH}_{2} \mathrm{Cl}_{2}(6 \mathrm{ml})$ the samples were analysed by GLC.

\subsection{Computational details}

Structures were preoptimised using the RI-method [11] as implemented in the TURBOMOLE [12,13] program package with Ahlrichs triple zeta basis [14] (TZVP) and the BP-86 functional. These were followed by further optimisations using the B3LYP functional and the TZVP basis set.

Possible transition states were determined by relaxed scans along the reaction coordinate (step size of $0.05 \AA$ ). For the reactants and the products frequency analyses have been carried out with the Gaussian 98 [15] program package using the B3LYP functional as described in the literature [16-18] and Ahlrichs triple zeta basis [14] as implemented in TURBOMOLE.

Using Gaussian 98 full optimisations of the transition states for $7 \mathbf{a}$ and $\mathbf{7 b}$ resulted in barrier heights of $76 \mathrm{~kJ}$ $\mathrm{mol}^{-1}$ at $2.19 \AA$ and $70 \mathrm{~kJ} \mathrm{~mol}^{-1}$ at $2.15 \AA$, respectively, which agree well with the results of the relaxed scans $\left(78 \mathrm{~kJ} \mathrm{~mol}^{-1}\right.$ at $2.25 \AA$ and $72 \mathrm{~kJ} \mathrm{~mol}^{-1}$ at $2.10 \AA)$. The full TS optimisations had imaginary frequencies of $473 \mathrm{i} \mathrm{cm}^{-1}$ and $474 \mathrm{icm}^{-1}$, respectively, with motion corresponding purely to the formation of the $\mathrm{C}-\mathrm{C}$ bond. The geometries determined from the full TS optimisations and the relaxed scans are also in excellent agreement and so it can be safely assumed that this approximation leads to negligible errors and thus, the remaining transition state structures calculated from the relaxed scans are reasonable. Solvent models were not used in these calculations, as the intramolecular nature of the reactions should negate the importance of solvent effects.

Initial calculations were done using a variety of compounds to determine which multiplet was the ground state and for all systems the sextet was found to be more stable than the quartet by $119 \mathrm{~kJ} \mathrm{~mol}^{-1}$ or the doublet by $142 \mathrm{~kJ} \mathrm{~mol}^{-1}$.

\section{Supplementary material}

Supplementary information containing tables with bond lengths and angles as well as atomic coordinates of structures $\mathbf{5 c}, \mathbf{5 d}, \mathbf{7 c}$, and $\mathbf{7 d}$ are available from the authors on request.

\section{Acknowledgements}

We gratefully acknowledge financial support from the Fonds der Chemischen Industrie, the Deutsche Forschungsgemeinschaft and the Graduiertenkolleg "Synthetische, mechanistische und reaktionstechnische Aspekte von Metallkatalysatoren". A generous amount of computer time has been granted from the TU Berlin and the Hochleistungsrechenzentrum Stutgart. We acknowledge Dr. Angelika Baro, Universität Stuttgart, for her assistance in preparing this manuscript. 


\section{References}

[1] Reviews: (a) E.D. Bergmann, D. Ginsburg, R. Pappo, Org. React. 10 (1959) 179-555; (b) D.A. Oare, C.H. Heathcock, in: E.L. Eliel, S.H. Wilen (Eds.), Topics in Stereochemistry, vol. 19, Wiley Interscience, New York, 1989, pp. 227-407; (c) P. Perlmutter, Conjugate Addition Reactions in Organic Synthesis, Tetrahedron Organic Chemistry Series vol. 9, Pergamon, Oxford, 1992.

[2] Review: J. Christoffers, Eur. J. Org. Chem. (1998) 1259.

[3] Review: J. Christoffers, Synlett (2001) 723.

[4] (a) J. Christoffers, Chem. Commun. (1997) 943;

(b) J. Christoffers, J. Chem. Soc. Perkin Trans. 1 (1997) 3141;

(c) J. Christoffers, H. Oertling, N. Önal, J. Prakt. Chem. 342 (2000) 546;

(d) J. Christoffers, Tetrahedron Lett. 39 (1998) 7083;

(e) J. Christoffers, H. Oertling, Tetrahedron 56 (2000) 1339;

(f) J. Christoffers, H. Oertling, M. Leitner, Synlett (2000) 349

[5] References cited in: Gmelins Handbuch der Anorganischen Chemie, Eisen, vol. 59 B, Verlag Chemie, Berlin, 1932, pp. 554560.

[6] (a) P. Kocovsky, D. Dvorak, Tetrahedron Lett. 27 (1986) 5015; (b) P. Kocovsky, D. Dvorak, Collect. Czech. Chem. Commun. 53 (1988) 2667.

[7] G. Gumbel, H. Elias, Inorg. Chim. Acta 342 (2003) 97.

[8] V. Gallo, P. Mastrorilli, C.F. Nobile, G. Romanazzi, P.G. Suranna, J. Chem. Soc. Dalton Trans. (2002) 4339.
[9] S. Kobayashi, K. Kakumoto, M. Sugiura, Org. Lett. 4 (2002) 1319.

[10] J. Christoffers, Org. Synth. 78 (2000) 249.

[11] M. v. Arnim, R. Ahlrichs, J. Comp. Chem. 19 (1998) 1746.

[12] R. Ahlrichs, M. Bär, M. Häser, H. Horn, C. Kölmel, Chem. Phys. Lett. 162 (1989) 165.

[13] O. Treulter, R. Ahlrichs, J. Chem. Phys. 102 (1995) 346.

[14] A. Schäfer, C. Huber, R. Ahlrichs, J. Chem. Phys. 100 (1994) 5829.

[15] M.J. Frisch, G.W. Trucks, H.B. Schlegel, G.E. Scuseria, M.A. Robb, J.R. Cheeseman, V.G. Zakrzewski, J.A. Montgomery, Jr., R.E. Stratmann, J.C. Burant, S. Dapprich, J.M. Millam, A.D. Daniels, K.N. Kudin, M.C. Strain, O. Farkas, J. Tomasi, V. Barone, M. Cossi, R. Cammi, B. Mennucci, C. Pomelli, C. Adamo, S. Clifford, J. Ochterski, G.A. Petersson, P.Y. Ayala, Q. Cui, K. Morokuma, P. Salvador, J.J. Dannenberg, D.K. Malick, A.D. Rabuck, K. Raghavachari, J.B. Foresman, J. Cioslowski, J.V. Ortiz, A.G. Baboul, B.B. Stefanov, G. Liu, A. Liashenko, P. Piskorz, I. Komaromi, R. Gomperts, R.L. Martin, D.J. Fox, T. Keith, M.A. Al-Laham, C.Y. Peng, A. Nanayakkara, M. Challacombe, P.M.W. Gill, B. Johnson, W. Chen, M.W. Wong, J.L. Andres, C. Gonzalez, M. Head-Gordon, E.S. Replogle, J.A. Pople, Gaussian 98 (Revision A.1x), Gaussian, Inc., Pittsburgh, USA, 2001.

[16] A.D. Becke, Phys. Rev. A 38 (1988) 3098.

[17] A.D. Becke, J. Chem. Phys. 98 (1993) 5648.

[18] C. Lee, W. Yang, R.G. Parr, Phys. Rev. B 37 (1988) 785. 